\title{
Monetary Growth Theory under Perfect and Monopolistic Competitions
}

\author{
Masayuki Otaki ${ }^{1}$, Masaoki Tamura² \\ ${ }^{1}$ Institute of Social Science, University of Tokyo, Tokyo, Japan \\ ${ }^{2}$ Institute of Innovation Research, Hitotsubashi University, Tokyo, Japan \\ Email: ohtaki@iss.u-tokyo.ac.jp, masaoki.tamura@iir.hit-u.ac.jp
}

Received May 13, 2013; revised June 13, 2013; accepted July 13, 2013

Copyright (C) 2013 Masayuki Otaki, Masaoki Tamura. This is an open access article distributed under the Creative Commons Attribution License, which permits unrestricted use, distribution, and reproduction in any medium, provided the original work is properly cited.

\begin{abstract}
This article analyzes the difference of properties of economic growth theory between perfect and monopolistic competition. Whether or not capital investment is constrained by effective demand is the crucial factor which characterizes economic growth theories in different degree of competition. Whenever each firm faces a downward sloping demand curve the location of which is determined by the strength of effective demand (i.e., the real GDP), its capital accumulation is inevitably constrained by effective demand. Thus, as far as business environment is kept unchanged, so is capital investment. However, when the good market is perfectly competitive, firms never perceive such demand constraint, thereby capital investment advancing autonomously independent of the phase of business cycle. An important macroeconomic implication of such a difference of the attitude toward capital investment is as follows. When an economy is in perfect competition, capital investment becomes an independent driving force of economic growth as Keynes considers, although it is subject to other independent expenditure (e.g., the government expenditure) and falls into a subsidiary component of effective demand otherwise.
\end{abstract}

Keywords: Sustainability of Fiscal Expenditure; Monetary Economic Growth Theory; Investment Theory under General Equilibrium

\section{Introduction}

It is almost unknown how the market structure of goods markets affects economic growth in a monetary economy. Although Dixit and Pindyck [1] and Smets [2] built models of investment function under uncertainty and pointed out that the function depends on the level of effective demand, it is not their concern with how such investment relating to economic growth as a whole each other. Otaki [3] developed a general equilibrium growth model under monopolistic competition, and also found that there exists no endogenous economic force for sustainable growth in a monetary economy.

In his seminal work, Uzawa [4] analyzed properties of the investment function under perfect competition in the context of general equilibrium model. Although his theory entirely excludes the existence of money, he found that the optimal investment ratio to capital is free from the level of effective demand. The optimal ratio is dependent on the profit rate which is endogenously deter- mined only by relative prices. Such a prominent property of the investment function implies that, differing from the monopolistic competition case analyzed by Otaki [3], capital investment enables an economy to sustain its growth. This is because the accumulated past capital investments (i.e., existing capital stock itself) empowers current investment without referring to the condition of effective demand ${ }^{1}$, and the resources are rewarded by whole earned quasi rents within the firm.

The main theoretical issue addressed in this article is to check the validity of Uzawa's [4] assertion that capital investment calls forth future investment expansion under

\footnotetext{
${ }^{1}$ It is quite ambiguous why more capitals enhance more investment in Uzawa [4]. He attributes such a property to the existence of managerial resources. However, it seems difficult to exhibit the substance of managerial resources. Otaki [5], instead, introduces the concept of dexterity of labor forces, which provides physical capital with positive externalities such as process innovations. A firm is regarded as an ingenious device for the internalization of such externalities, and thus, since there is no limit to sale under perfect competition, a firm attains sustainable growth together with the accumulation of dexterity.
} 
perfect competition and that economic growth is sustainable even in a monetary economy. The result is as follows. Since the effective demand principle works because of the indeterminacy of equilibrium price sequence (see, for more detail Otaki [6]), an economy is not necessarily able to attain GDP which guarantees the full resource utilization even though goods markets are competitive. However, since capital investment becomes an autonomously expanding independent expenditure of effective demand, the suspending power to economic growth becomes fortified compared with the case of monopolistic competition as analyzed in Otaki [3]. Consequently, government deficits necessary for attaining full resource utilization grows only at a constant rate, which is equalized to the GDP growth rate, although such a rate is accelerated together with capital accumulation in monopolistic competition case (see Theorem 2 in Otaki [3]).

The remainder of this paper is organized as follows. We construct and analyze the two-period overlappinggenerations monetary growth model with impure altru$i s m^{2}$ in Section 2. In Section 3, we analyze the relationship between the competitiveness of markets and the fiscal sustainability. Section 4 contains concluding remarks.

\section{The Model}

\subsection{Structure of the Model}

There are two strata in this economy: employers and employees. Each employee provides his unit labor when he is young at his discretion. The disutility is denoted as $\alpha$. His lifetime utility which comes from the consumption stream $\left(c_{1 t}, c_{2 t+1}\right)$ is a Cobb-Douglas function (note that such a function is common with employers). Thus, the lifetime utility $U$ is defined as

$$
U \equiv\left[c_{1 t}\right]^{1-s}\left[c_{2 t+1}\right]^{s}-\delta_{t} \cdot \alpha, \quad 0<s<1,
$$

where $\delta_{t}$ is a definition function the value of which takes unity when employed and zero when unemployed. Without loss of generality and mainly for simplifying the calculation, we assume that the economy is located at the full employment equilibrium (The full-employment level is fixed to unity).

On the other hand, each employer hires employees to produce goods and gain profit when he is young. In addition, he makes investments for the next generation, because we assume that every employer holds impure altruism; he not only concerns with his own lifetime utility but also descendant's utility. His inheritances are seeds of the dexterity of future employees via investments on

\footnotetext{
${ }^{2}$ See, for example, Acemoglu [7] on the detail of impure altruism.
}

education (we assume that it takes a considerable length of time for such education being effective). His investments enable young employers in the next period to hire employees. There is no disutility of labor in this stratum.

The government newly issues fiat money to finance its fiscal expenditures which is, for simplicity, bear no additional utility in the private sectors. It is also assumed that the government pays real dole $d$ in proportion to his dexterity $L_{t}$, which is null since our reference point is the full-employment equilibrium. The arbitrage condition within the labor market requires

$$
p_{t} d=W_{t}^{R} L_{t-1}
$$

where $W_{t}^{R}$ is the nominal reservation wage, which is endogenously determined as below.

The budget constraint of the government becomes

$$
\begin{aligned}
& M_{t}-M_{t-1}=p_{t} G_{t} \\
& \Leftrightarrow \frac{M_{t}}{p_{t} L_{t-1}}-\frac{M_{t-1}}{p_{t} L_{t-1}}=\frac{G_{t}}{p_{t} L_{t-1}}, \\
& \Leftrightarrow g_{t}=m_{t}-\frac{m_{t-1}}{\left[1+\pi_{t}\right][1+\theta]}
\end{aligned}
$$

where

$$
m_{t} \equiv \frac{M_{t}}{p_{t} L_{t-1}}, \quad g_{t} \equiv \frac{G_{t}}{p_{t} L_{t-1}}, \quad \pi_{t} \equiv \frac{p_{t+1}}{p_{t}}-1, \quad \theta \equiv \frac{L_{t-1}}{L_{t-2}}-1 .
$$

$p_{t}$ is current price of the good which is produced in the economy. $g_{t}$ is the real government expenditure per an efficient unit labor force. $L_{t}$ is the labor force per an employee measured by the efficiency unit. $\theta$ denotes the degree of progress in dexterity nurtured by the employer's capital investment.

\subsection{Agent's Maximization Problems}

\subsubsection{Employers}

An employer is assumed to be impure altruistic. His marginal substitution rate between his own consumption and his descendant's income is fixed to unity. Furthermore, since the marginal substitution rate between current and future consumption is equalized to the gross inflation rate $1+\pi_{t}$, which is common in both capital investment and money hoarding decisions, the optimal capital investment decision problem becomes equivalent to the maximization problem on the discounted net cash flow obtained from capital. Accordingly, the optimal economic behavior of an employer can be expressed by the following equations ${ }^{3}$.

\footnotetext{
${ }^{3}$ Although, for simplicity, we henceforth assume that the nominal wage is equal to the nominal reservation wage, it is natural to consider that the nominal wage is determined through bargaining process since labor forces are regarded as quasi fixed production factor. However, even though we introduce such negotiation process into the model, obtained results are kept intact. For detail, see Otaki [8].
} 


$$
\begin{gathered}
S^{E R}=\left[r L_{t-1}-W_{t}^{R} L_{t-1}\right], \\
\phi^{\prime}\left(\theta^{*}\right)=r\left[1+\pi^{*}\right],
\end{gathered}
$$

where $S^{E R}$ is the aggregate savings of employer stratum. $r$ is the rate of return from skilled labor force. $\phi$ denotes the average adjustment cost for educating and nurturing dexterity, which is defined as

$$
\Phi\left(L_{t}, L_{t-1}\right) \equiv \phi(\theta) L_{t-1}, \phi^{\prime}>0, \phi^{\prime \prime}>0,
$$

where $\Phi$ is the total adjustment cost.

\subsubsection{Employees}

Since the lifetime utility function of consumption is Cobb-Douglas form, the aggregate savings of employees $S^{E E}$ is

$$
S^{E E}=s \cdot W_{t}^{R} L_{t-1} .
$$

In addition, the indirect lifetime utility $I U_{t}$ becomes

$$
I U_{t}=\frac{W_{t}^{R} L_{t-1}}{\left[p_{t}\right]^{1-s}\left[p_{t+1}\right]^{s}} \Rightarrow W_{t}^{R} L_{t-1}=\alpha\left[p_{t}\right]^{1-s}\left[p_{t+1}\right]^{s} .
$$

Combining (7) with (2), we obtain the following fundamental equation concerning the dynamic motion of equilibrium price sequence.

$$
p_{t} d=\alpha\left[p_{t}\right]^{1-s}\left[p_{t+1}\right]^{s} \Rightarrow 1+\pi^{*}=\left[\frac{d}{\alpha}\right]^{\frac{1}{s}}
$$

\subsection{Market Equilibrium: The Relationship between Market Competitiveness and Autonomy of Capital Investment}

We have two markets in the model: the good market and money market. By Walras' law, we can concentrate the equilibrium condition for the good market. By adding up (4) and (6), the saving function of the economy as a whole $S_{t}$ is

$$
S_{t} \equiv s \cdot r L_{t-1} .
$$

To avoid the unessential non-linearity in the investment function, we assume that the average adjustment cost function $\phi$ is a power function. That is,

$$
\phi(\theta) \equiv \theta^{\beta}, \quad \beta>1 \text {. }
$$

Then, from the optimality condition for the optimal capital investment (5), the investment function $I_{t}$ is derived as

$$
I_{t}=\phi(\theta) L_{t-1}=\left[\frac{r}{\beta}\left[1+\pi^{*}\right]\right]^{\frac{\beta}{\beta-1}} L_{t-1},
$$

where $1+\pi^{*}$ is the equilibrium inflation rate in (8).
Furthermore we assume that, differing from Otaki [3], the growth rate of fiscal deficits per labor force measured in efficiency unit is set at zero and $m=m_{t}=m_{t-1}$ holds. The government budget constraint (3) is transformed into

$$
g=\left[1-\frac{1}{\left[1+\pi^{*}\right]\left[1+\theta^{*}\right]}\right] m .
$$

Equations (9), (10) and (11) lead us to the following equilibrium condition for the good market normalized by existing labor force in terms of efficiency unit $L_{t-1}$ as

$$
\begin{aligned}
& s \cdot r=\left[\frac{r}{\beta}\left[1+\pi^{*}\right]\right]^{\frac{\beta}{\beta-1}}+g+\frac{1}{\left[1+\pi^{*}\right]\left[1+\theta^{*}\right]} m \\
& \Rightarrow s \cdot r=\left[\frac{r}{\beta}\left[1+\pi^{*}\right]\right]^{\frac{\beta}{\beta-1}}+m,
\end{aligned}
$$

where the third term of the right-hand side of above equation in (12) is the expenditure of the old generation per efficiency unit of labor force. As far as the real cash balance in terms of efficiency unit of labor force $m$ is determined so that both sides of (12) are equalized, the economy can sustain the full capacity utilization ${ }^{4}$. Since the first term of the right-hand side of (12) is the contribution of the capital investment to the growth rate of GDP per capita, this implies, in contrast with Otaki [3], that the capital investment autonomously and steadily grows free from the level of effective demand.

\section{The Analysis: Market Competitiveness and the Fiscal Sustainability}

Since it is apparent that the monetary growth rate under the full capacity utilization equilibrium is equal to that of nominal GDP, $\left[1+\pi^{*}\right]\left[1+\theta^{*}\right]$, we finally obtain the following theorem.

\section{Theorem}

The growth of the monetary economy under perfect competition is sustainable in the sense that the ratio of public debts to nominal GDP is kept constant over time.

The above theory is quite contrastive with properties of the monetary growth model under monopolistic competition in Otaki [3], in which the public debts-nominal GDP ratio $\frac{G_{t}}{Y_{t}}$ is explosive. The decisive economic reason whether such a ratio is explosive or not is whether employers are subject to the effective demand constraint. Employers' capital investment is substantively affected by whether or not they face the demand constraint.

\footnotetext{
${ }^{4}$ As Otaki [9] argues, if individuals rationally believe that the future purchasing power of money is unaffected by the change of current nominal money supply $M_{t}$ (i.e., money is credible), current price $p_{t}$ also becomes insensitive to $M_{t}$ (see (8), and thus, the government can control the real cash balance.
} 
In perfect competition case, capital investment enables every employer to expand the production without the demand constraint in the long run. It immediately implies that the aggregate capital investment is autonomously expanded, and hence it consists of an endogenous force of economic growth as incessant effective demand stimuli. The above perfect competitiveness case is a limit case of Otaki [3] in which the price elasticity of each firm's good $\eta \rightarrow+\infty$.

Meanwhile, capital investment is constrained by the effective demand in case of monopolistic competition $(0<\eta<+\infty)$. In other words, capital investment does not have a power enough to create new additional demand per se. Capital investment enables every employer only to reduce production cost. Thus, other exogenous expansionary shocks, such as acceleration of fiscal expenditure, are indispensable with sustaining economic growth. Accordingly, fiscal deficits and the public debtsnominal GDP ratio become explosive as proved by Otaki [3].

To summarize, as goods are standardized, markets are more competitive and $\eta$ becomes large, the constraint of aggregate demand to which capital investment is subject fades away. Thus, capital investment is empowered enough to create new demand by itself and the fiscal sustainability is heightened. The limit case, where markets are under perfect competition, is precisely analyzed in this article because this is the most prominent case for exhibiting the relationship mentioned above.

\section{Conclusions}

This paper analyzed how market competitiveness relates to the sustainability of economic growth. The obtained result is as follows. Because there is no demand constraint whenever market is competitive, capital investment creates additional effective demand in the future by itself. Such fact implies that an economy steadily grows without unsustainable help from its government.

In turn, as Otaki [3] shows, goods provided in the economy are differentiated even narrowly and markets become less competitive, every employer perceives that he faces a downward-sloping demand function the location of which is determined by effective demand. Therefore, capital investment is subject to effective demand, thus, loses the driving force for economic growth. The progress of labor productivity by capital investment needs an explosive fiscal expenditure to maintain the full resource utilization equilibrium.

In this sense, competitiveness plays a key role on sustaining stable fiscal balance with moderate economic growth.

\section{REFERENCES}

[1] A. Dixit and R. Pindyck, "Investment under Uncertainty," Princeton University Press, Princeton, 1994.

[2] F. Smets, "Exporting versus FDI: The Effect of Uncertainty, Irreversibilities, and Strategic Interactions," Working Paper, Yale University, 1991.

[3] M. Otaki, "On the Endogenous Sustainability of Economic Growth: Why Is the Scale of Government Enlarged?" Theoretical Economics Letters, Vol. 3, No. 3, 2013, pp. 159-163. doi: 10.4236/tel.2013.33026

[4] H. Uzawa, "Time Preference and the Penrose Effect in a Two-Class Model of Economic Growth," Journal of Political Economy, Vol. 77, No. 4, 1969, pp. 628-652. doi:10.1086/259554

[5] M. Otaki, "The Evaluation of Dexterity and a Theory of the Growth of a Firm," Modern Economy, Vol. 4, No. 3A, 2013, pp. 226-229. doi:10.4236/me.2013.43A025

[6] M. Otaki, "The Dynamically Extended Keynesian Cross and the Welfare-Improving Fiscal Policy," Economics Letters, Vol. 96, No. 1, 2007, pp. 23-29. doi:10.1016/j.econlet.2006.12.005

[7] D. Acemoglu, "Introduction to Modern Economic Growth," Princeton University Press, Princeton, 2009.

[8] M. Otaki, "A Welfare Economics Foundation for the FullEmployment Policy," Economics Letters, Vol. 102, No. 1, 2009, pp. 1-3. doi:10.1016/j.econlet.2008.08.003

[9] M. Otaki, "A Pure Theory of Aggregate Price Determination," Theoretical Economics Letters, Vol. 1, No. 3, 2011, pp. 122-128. doi:10.4236/tel.2011.13026 